\title{
Escoando Imagens \\ leaking Images
}

\author{
Elisandro Rodrigues -UFRGS/UFSM, elisandromosaico@gmail.com \\ Helga Correa - UFSM, helgacor@gmail.com
}

Resumo: O presente artigo busca aproximar o pensamento deleuziano da produção audiovisual. Toma-se para análise os espaços e intervalos quaisquer e os movimentos de afecto e afecção de Spinoza. Tece-se uma cartografia dos inventários de experimentações audiovisuais e de materialidade afectiva pelo projeto "Cartografias Infantis: Biografemas de Instantes Quaisquer" de onde brotou o audiovisual 'As Cores da Esperança'. O objetivo principal deste artigo é falar de uma experiência de formação e de trabalho que utiliza a imagem, o audiovisual, o vídeo e as Tecnologias de Informação e Comunicação [TIC] como disparador de processos de aprendizagem, como instantes quaisquer que agenciam afecções.

Palavras-chave: Audiovisual, TIC, Biografemas, Afectos, Cartografia

Abstract: This article seeks to close the Deleuzian thought of audiovisual production. Takes to analyze the spaces and all ranges and movements of affection and affection of Spinoza. Weaves a mapping inventory of audiovisual trials and affective materiality of the project "Kids Cartographies: Any Biographeme of Moments" that yielded the audiovisual 'Colours of Hope'. The main purpose of this article is talking about an educational experience and work that uses image, audiovisual, video and Technologies of Information and Communication [ICT] to trigger learning processes, as any moment touting disorders.

Key-words: Audiovisual, ICT, biographeme, Affects, Cartography

\section{_ Dos pormenores que escoam}

“O cinema possui apenas um personagem: o pensamento" [Deleuze]

Tentarei, de uma forma fragmentada, realizar, nesse artigo, uma aproximação entre o audiovisual e a terceira Imagem-Movimento proposta por Deleuze, nos seus livros, sobre cinema, a imagem-afecção. Para esse autor, as imagens-movimentos se dividem em três: imagem-percepção, imagem-ação e imagem-afecção. Para tanto, tomarei como base o pensamento de Spinoza para falarmos de afecto [afeto].

\#

Para isso, primeiro, pergunto-me: Como captar uma imagem poética, ou como colocar uma poesia em imagem? Quais são os afetos ${ }^{1}$ que uma imagem cria? Como movimentar uma imagem poética? São experimentos difíceis de cartografar. Exigem um salto e uma abertura para as experimentações. Deve-se estar atento aos hiatos e intervalos de tempo, para que as imagens

1 É importante, já de saída, realizar uma distinção, Spinoza, no seu livro Ética, trabalha com duas concepções, duas palavras que, por vezes, podem acabar se confundindo. Quando o autor utiliza a palavra Affectus, está falando de afetos e, quando utiliza affectio, está falando de afecção. Utilizarei a palavra afeto, ou afecto, no decorrer deste texto, partindo da concepção de affectus de Spinoza, o mesmo procedimento com afecção, que quer dizer affectio. 
possam escoar em a[in]cidentes ${ }^{2}$.

Podemos tentar realizar essas capturas poéticas e afetivas de diferentes jeitos: com os olhos, com o pincel, com um estêncil, com um lápis colorido numa folha de papel, com um giz na calçada, com as imagens gravadas na memória, com a fotografia. Por exemplo, se tentasse fotografar o silêncio, de forma poética e afectiva, como seria?

\#

É difícil fotografar o silêncio "entretanto tentei. Eu conto: Madrugada a minha aldeia estava morta. Não se ouvia um barulho, ninguém passava entre as casas. Eu estava saindo de uma festa. Eram quase quatro da manhã. Ia o Silêncio pela rua carregando um bêbado"3. Sem pensar muito, num instinto de quem quer guardar e coletar imagens que escapam, "preparei minha máquina”.

"O silêncio era um carregador? Fotografei esse carregador. Tive outras visões naquela madrugada. Preparei minha máquina de novo" . Estar atento, pode-se dizer que é um primeiro movimento para disparar o obturador da máquina fotográfica a qualquer momento. Entretanto, o disparo não pode ser feito de qualquer forma, ele exige um pensar na imagem, no que queremos gravar no pedaço de filme que fica enquadrado no espelho da máquina.

Deve-se pensar nos disparos, ainda mais eu, que ando com uma máquina fotográfica analógica, dessa forma, não se tem como saber como a imagem ficou, ela não tem a tecnologia das atuais, e não se pode disparar muitas poses em sequência, o filme comporta apenas 24 fotos. Tenho que construir um tempo de espera, um tempo onde o pensamento necessita de um intervalo para pensar em possíveis imagens a serem capturadas.

“Tinha um perfume de jasmim num beiral de um sobrado. Fotografei o perfume. Vi uma lesma pregada mais na existência do que na pedra. Fotografei a existência dela. Vi ainda azulperdão no olho de um mendigo. Fotografei o perdão. Vi um paisagem velha a desabar sobre uma casa. Fotografei o sobre. Foi difícil fotografar o sobre" ${ }^{2}$. A cada esquina, a cada rua que os pés pisavam, a cada dobra de vento outras imagens iam se formando, se construindo em pormenores ${ }^{6}$. As imagens, nesses intervalos de tempo e de silêncio, desdobram-se em biografemas $^{7}$.

\section{\#}

O biografema é como um punctum, uma pequena "picada, pequeno orifício, pequena

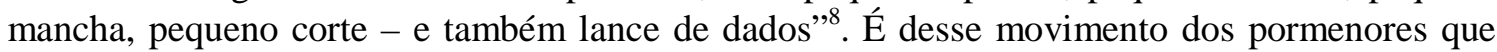
salta o biografema, aquilo que aparece pequeno, mas que fere o olhar e o pensamento. Entendo, aqui, o biografema como método de escrita de vida a partir de suas intensidades, de seus afetos, seus fragmentos e detalhes. É escrever uma vida em [e a partir de] fragmentos.

Faz-se, no incidente, "menos contundente que o acidente, mas mais inquietante", nesse a[in]cidente. Faz-se, no "recolher certos traços, certos biografemas", que podem ser "minitextos, recados, haicais, anotações, jogos de sentidos, tudo o que cai como uma folha"10. Escrever biografemas é traçar, delicadamente, um rizoma, uma vida [res]pingada, cartografada.

"Por fim cheguei a Nuvem de calça. Representou pra mim que ela andava na aldeia de braços com Maiakovski - seu criador. Fotografei a Nuvem de calça e o poeta"11. Manoel de

\footnotetext{
2 Jogo entre duas palavras: acidentes - instantes quaisquer que provocam um acontecimento; e incidentes de Barthes [2004], que são os pormenores de uma vida.

3 [BARROS, 2010]

4 [Ibd.]

5 [Ibd.]

6 [RODRIGUES, 2011]

7 Como nos diz Barthes [2010, p.39] "do mesmo modo, gosto de alguns traços biográficos que, na vida de um escritor, me encantam tal como certas biografias: chamei a esses traços $<<$ biografemas $>>$ ”.

8 [BARTHES, 2010, p. 35]

9 [CORAZZA, 2010, p.97]

10 [BARTHES, 2003, p. 166-167]

11 [BARROS, 2010]
} 
Barros cartografa, em seus poemas pormenores de uma vida, de ações, de estéticas que escapam aos olhos. Esses pormenores são detalhes "e é a partir dele que o olhar atravessa as fotos"12, para ver as pequenas coisas, os biografemas de uma vida.

No contemporâneo em que estamos mergulhados, a delicadeza e a sensibilidade de captar os pequenos instantes quaisquer ${ }^{13}$ de nosso cotidiano escampam. Precisamos de instrumentos e tecnologias leves ${ }^{14}$ para criar outros modos de olhar, outros modos de ver e de viver esses instantes captados e vividos. "Nesse espaço habitualmente unário, por vezes (mas, infelizmente, raras vezes) um $<<$ pormenor $>>$ chama a atenção. Sinto que a sua presença por si só modifica a minha leitura, que é uma nova foto que contemplo"15 uma nova realidade, uma mudança nas percepções e entendimentos, o pormenor acontece nesses a[in]cidentes, nesse caminhar na madrugada, ou de quando não esperamos que algo aconteça, ou seja, em instantes quaisquer ${ }^{16}$.

\#

Penso este texto para dar conta de alguns pormenores que não cartografamos, para não deixar que essas imagens se cristalizem, para escoar essas imagens por outros espaços, de outros jeitos. Sendo assim, o objetivo principal deste artigo é falar de uma experiência de formação e de trabalho que utiliza a imagem, o audiovisual, o vídeo e as Tecnologias de Informação e Comunicação [TIC] como disparador de processos de aprendizagem, como instantes quaisquer que agenciam ${ }^{17}$ afecções.

Tentando responder a esse objetivo, relato a experiência do projeto 'Cartografias Infantis: Biografemas de Instantes Quaisquer", de onde brotou o audiovisual 'As Cores da Esperança', para isso, parto da reflexão sobre um Objeto de Aprendizagem, construído no decorrer da especialização em TIC Aplicadas à Educação. A hipótese central deste estudo parte do entendimento do audiovisual como uma ferramenta tecnológica possível de utilização em sala de aula para o desenvolvimento e aprendizagem.

\#

\section{_cartografando imagens [ou de uma metodologia]}

A metodologia de pesquisa utilizada neste artigo baseia-se no referencial pós-critico, no pós-estruturalismo e na filosofia da diferença. Entendo que uma metodologia de pesquisa é sempre pedagógica, pois se refere a um como fazer ${ }^{18}$. O “como fazer” pesquisa, em Tecnologias da Informação e Comunicação, usando referenciais pós-críticos, e da filosofia da diferença, é uma aposta nova, que se mostra como um importante inovador metodológico no processo de pesquisa ${ }^{19}$.

Essa aposta pedagógica e metodológica experimenta, no ato de pesquisar os afetos

\section{2 [BARTHES, 2003, p. 166-167]}

13 “pode ser regular ou singular, ordinário ou marcante” [DELEUZE,1985, p. 14]. Instante/momentos quaisquer é um movimento que remete a uma mudança, ao que transforma minimamente um acontecimento, que coloca em operação o que estava em suspensão.

14 [MERHY, 1997; 2002]. Tecnologia Leve é um termo que Merhy usa no campo das práticas em saúde, remete ao território do trabalho vivo da micropolítica dos afetos, enquanto Tecnologia Dura referenda-se a dimensão dos equipamentos de saúde e, também, da burocratização do amanhã [SOUSA, 2007].

15 BARTHES, 2009, p.51]

16 O espaço, instante quaisquer [DELEUZE, 1985; 2005], é um atopon, um não lugar, um lugar onde o possível pode acontecer. Para Claudio Ulpiano, em sua aula sobre imagem-afecção, em 1995 [disponível em http://claudioulpiano.org.br.s87743.gridserver.com/?p=116], o espaço qualquer "é quando alguma coisa quer expressar-se como ela é - na sua essência...é um espaço qualquer! Qualquer coisa serve para aquilo se expressar”. $17 \mathrm{O}$ agenciamento comporta dois segmentos "um de conteúdo, outro de expressão. De um lado, ele é agenciamento maquínico de corpos, de ações, de paixões, mistura de corpos reagindo uns sobre outros; de outro, agenciamento coletivo de enunciação, de atos e de enunciados, transformações incorpóreas atribuídas aos corpos. Mas, segundo um eixo vertical orientado, o agenciamento tem, ao mesmo tempo, lados territoriais ou reterritorializados, que o estabilizam, e pontas de desterritorialização, que o impelem”. [DELEUZE; GUATTARI, 2003, p. 112]. Pensa-se assim no audiovisual como potencializador de [des]territorialização, de jeitos que expressão e criam vidas.

18 [MEYER; PARAÍSO, 2012, p. 15]

19 [MARTINES; MACHADO; COLVERO, 2013, p. 203] 
vividos, as inquietações que brotam das perguntas que se vai fazendo ao desenhar os caminhos que se quer realizar, e, a cada passo da execução desse desenho, podemos redesenhar e mudar de traçado, de trajeto.

Pesquisar, com esse intuito, "aciona audições e visões, gostos e cheiros, toques e forças" ${ }^{20}$. Dessa forma, entendo metodologia, num pesquisar pós-critico, da filosofia da diferença, "como um certo modo de perguntar, de interrogar, de formular questões" ${ }^{21}$, que não são formatados, mas que se permitem à rasura e ao erro.

Com isso, pode-se eliminar as barreiras entre as disciplinas para assim deslocar, descolar as linhas que separam "ciência e literatura, conhecimento e ficção, arte e ciência, filosofia e comunicação. Explodimos as separações entre teoria e prática, discurso e realidade, conhecimento e saberes do senso comum, representação e realidade" ${ }^{22}$. Utilizo, como opção metodológica, a Cartografia, proposta por Gilles Deleuze e Felix Guatarri.

A cartografia, diferente do decalque do mapa, propõe linhas rizomáticas de análise dos processos de pesquisa e do que se é pesquisado. Dessa forma, se constrói mapas de análise, de sentidos, aonde se vai acompanhando suas transformações. Ao pensar no estudo de audiovisuais, e de experiências vividas, a cartografia mostra-se potente no seu uso, sendo, assim, "a cartografia como método de pesquisa é o traçado desse plano da experiência, acompanhando os efeitos (sobre o objeto, o pesquisador, e a produção do conhecimento) do próprio percurso da investigação",23.

O processo cartográfico de pesquisa se deu na sistematização e no mapeamento das experiências com audiovisuais, e os desdobramentos afetivos na utilização do audiovisual como ferramenta de aprendizagem. Utilizar a cartografia, como analisador neste artigo, permite ver o audiovisual "por outras perspectivas que as técnicas e procedimentos costumeiramente usados na comunicação. Ela reconhece, igualmente, o espaço e a subjetividade na pesquisa - o que não é muito aceito na pesquisa em comunicação"24.

\section{_o Audiovisual como objeto de aprendizagem}

Durante o percurso da Especialização em TIC Aplicas à Educação, descobri um pouco mais dos movimentos de ensino e aprendizagem utilizando as ferramentas tecnológicas. Na disciplina "Ambientes Virtuais de Ensino e Aprendizagem”, sob orientação do Professor Claudio Afonso Baron Tiellet, ajudei a construir um Objeto de Aprendizagem [OA], utilizando o audiovisual $^{25}$ como intercessor do processo de aprender.

Os Objetos de Aprendizagem, ou objetos educacionais, são ferramentas de ensino reutilizáveis. Têm como suporte, como base, uma tecnologia e podem ser definidos como entidades digitais, ou não, e devem ser desenvolvidos para fins educacionais ${ }^{26}$. Podem ser conceitualizados como "segmentos de informação autônoma, ou seja, módulos de conteúdo, onde cada um apresenta recursos específicos de ensino, que podem ser utilizados tanto individualmente, quanto em conjunto com outros" ${ }^{27}$.

Os OA nos fornecem uma possibilidade maior de uso e reuso, podendo ser compartilhados, nas redes virtuais, "eles surgem como um recurso capaz de potencializar a reestruturação das práticas pedagógicas, criando novas maneiras de refletir sobre o uso da

20 [FREITAS; MACHADO, 2013, p. 239]

21 [Ibd., p. 16]

22 [PARAÍSO, 2012, p. 33]

23 [PASSOS; KASTRUP; ESCÓSSIA, 2009, pg. 17-18]

24 [AGUIAR; ROSÁRIO, 2012, pg.1272]

25 Trago, aqui, audiovisual quando me refiro a vídeos criados e editados com a finalidade pedagógica e educacional. É o produto gerado da interação da imagem com o som/áudio que desencadeiam um movimento imagético. Segundo a Lei 9610/98, art. 5, “Audiovisual - o que resulta da fixação de imagens com ou sem som, que tenha a finalidade de criar, por meio de sua reprodução, a impressão de movimento, independentemente dos processos de sua captação, do suporte usado inicial ou posteriormente para fixá-lo, bem como dos meios utilizados para sua veiculação”.

26 [REIS, 2010]

27 [MACHADO; SILVA, 2005, p. 02] 
comunicação, da informação e da interação” ${ }^{28}$. Os OA possibilitam uma captura do olhar, como em uma fotografia, que pode despertar um punctum, um interesse por aquele conteúdo, saber, ideia, conhecimento. São capazes de proporcionar um outro modo de olhar, de ver e interagir com o aprendizado.

O Objeto de Aprendizagem criado na disciplina "Ambientes Virtuais de Ensino e Aprendizagem" foi um audiovisual intitulado "Matéria de Poesia”29. De uma forma sensível, utilizou-se o recurso de imagens que potencializam outros sentidos juntamente ao áudio de poemas de Manoel de Barros. O vídeo fala das 'coisas nenhuma', dos pedaços, dos fragmentos e das pequenas coisas que servem para a poesia.

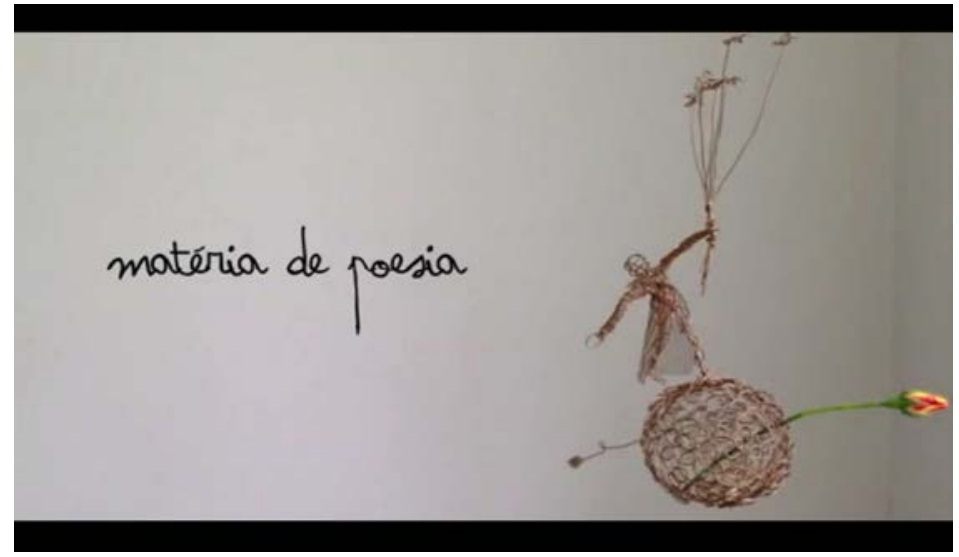

(Frame do OA Matéria de Poesia)

Trago, aqui, a experiência do 'Matéria de Poesia' para realizar um link com o que trarei, a seguir, e para dizer que o audiovisual pode ser trabalhado como um Objeto de Aprendizagem. O audiovisual, ao ser colocado em uma plataforma de vídeos, pode ser olhado, reolhado, compartilhado, baixado, pode ser exibido em diferentes lugares e espaços, tendo um alcance não imaginado.

Ao ser disponibilizado nos ambientes virtuais, passa a ser outra coisa, sofre uma mudança, não é apenas mais um vídeo, mas sim, um dispositivo e uma ferramenta que pode produzir afecções, criar redes e diálogos. Promove um discurso, uma ideia, um jeito de trabalhar com as informações, no caso do 'Matéria de Poesia', divulgando o que é um OA, a Especialização em TIC Aplicadas à Educação e a poesia de Manoel de Barros.

\section{_escoando imagens}

$$
\text { \# }
$$

Prolongo-me, nesses três primeiros fragmentos, fazendo um percurso ziquezagueante: 1) pela poesia e a captação de imagens poéticas pela fotografia para dizer que imagens criam afectos poéticos; 2) pelos [res]pingos imagéticos que falam de vidas que vivem em um plano de experiência e que podem ser cartografados; 3) dessas experiências pequenas que podem ser sistematizadas, das pequenas coisas que saltam, dos detalhes dos pormenores, o que chamo de biografemas. E digo de uma possibilidade de utilização, do audiovisual, na aprendizagem, em OA e nas TIC.

Esse percurso é necessário para falar, do que muitas vezes não se fala, dos instantes quaisquer que perdemos em meio à velocidade do cotidiano. Remeto-me, dessa forma, a experimentações vividas e, puxando delicadamente a memória, pude perceber que o escoamento da imagem está presente nos meus trabalhos em sala de aula. Construir escoamentos é sair de um território já endurecido, cristalizado.

Ulpiano $^{30}$ nos fala que a arte é uma prática a serviço da vida. Entendo dessa forma a

28 [AUDINO; NASCIMENTO, 2010, p. 130]

29 Esse Objeto de Aprendizagem está disponível no seguinte endereço:

http://santosmarcel7.wix.com/materiadepoesia

30 Em suas aulas em áudio, vídeo e transcritas no site que leva seu nome www.claudioulpiano.com.br . 
poesia, o audiovisual, como criação de biografemas, que impulsionam a vida como arte ${ }^{31}$. Ou seja, esse deslocamento do olhar do maior para o [por]menor, para os detalhes de uma experiência e de uma vivência, de colocar a vida em foco, é escoar [outras] imagens possíveis.

No desterritorializar que a cartografia propicia e motivado pela experiência da construção do audiovisual 'Matéria de poesia', decidi falar, neste artigo, sobre o documentário produzido através do projeto 'Cartografias Infantis: Biografemas de Instantes Quaisquer'. O documentário chama-se 'As Cores da Esperança ${ }^{132}$. Contar essa experiência é contar paixões alegres e espalhar afectos ao que acontece em sala de aula.

O projeto 'Cartografias Infantis: Biografemas de Instantes Quaisquer' foi o plano de intervenção com uma turma do quinto ano de uma escola da periferia do município de Sapucaia do Sul. Esse projeto aconteceu durante o segundo semestre letivo de 2012. Dentre outras coisas, pretendi transformar as aulas em espaços de produção e criação de outros sentidos na vida dos alunos. Para tanto, os recursos das TIC e das artes ${ }^{33}$ foram utilizados.

O título do projeto desdobrou-se em possibilidades de experimentações: cartografar os movimentos de desejo das crianças e adolescentes, utilizando o biografema, esse outro jeito de contar a vida através desses instantes, que poderiam vir a se tornarem quaisquer e importantes de serem contados. Escrevendo, dessa forma, as singularidades de vidas desses alunos, dos pormenores cotidianos. Trazendo a palavra pelo gesto, pela imagem e pela própria letra grafada.

Durante o segundo semestre letivo, de 2012, experimentou-se cores, jeitos potencializando os encontros e os processos de pensar uma vida. O projeto dividiu-se em dois momentos, o primeiro das sensações, e o segundo, das experimentações. No primeiro momento, das sensações, propiciou-se dar um outro corpo para o corpo. Os alunos puderam vivenciar e contar suas vidas através de exercícios e jogos de Teatro ${ }^{34}$; e, na experimentação, da escrita literária e poética, através das leituras de livros e poesias, suas sistematizações e encenações.
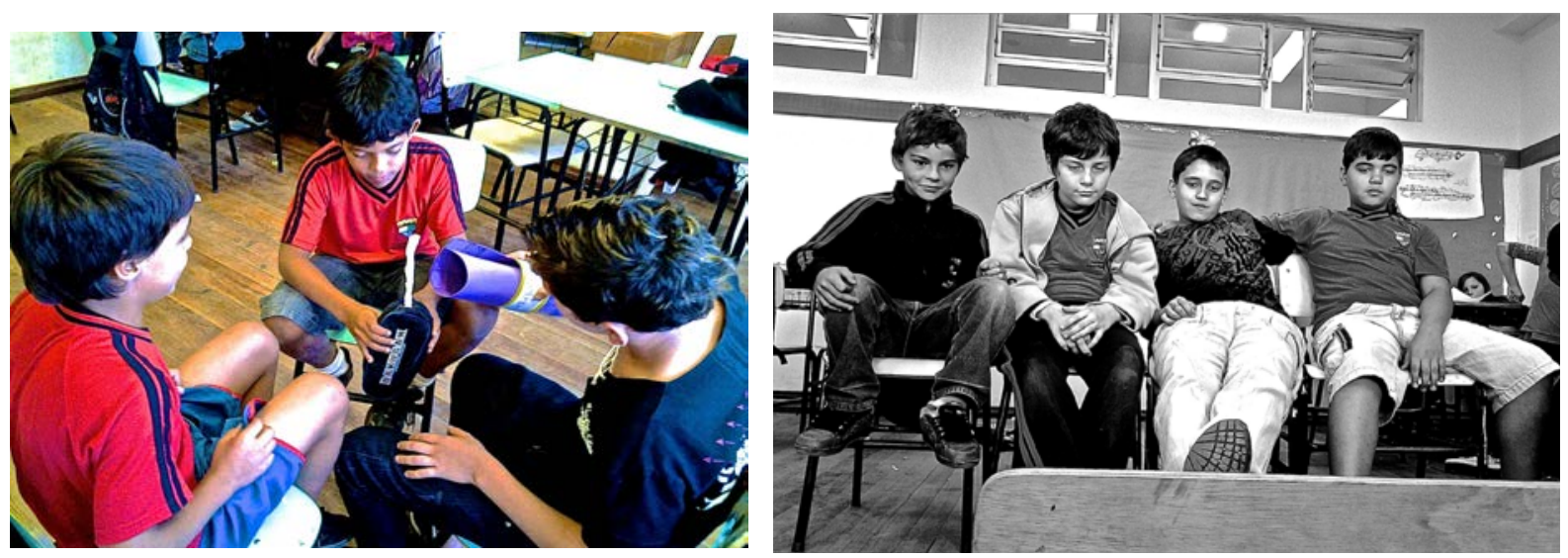

(Experimentações e jogos teatrais com alunos)

31 O que me surpreende, em nossa sociedade, é que a arte se relacione apenas com objetos, e não, com indivíduos ou a vida; e que também seja um domínio especializado, um domínio de peritos, que são os artistas. Mas a vida de todo indivíduo não poderia ser uma obra de arte? Por que uma mesa ou uma casa são objetos de arte, mas nossas vidas não? [FOUCAULT, 1994]

32 Este documentário foi realizado em parceria com Graciela Caputti, que realizou a captação das imagens.

33 É importante salientar que o projeto acontecia uma vez por semana. No dia do Planejamento da professora titular, Cristiane Santos, assumia a turma para a realização de experimentações e sensações. Cabe dizer, também, que o projeto não era isolado, ficando apenas uma atividade dispersa, mas sim, eram realizadas intervenções, planejamento e propostas conjuntas à professora titular. Dessa forma, o projeto tomou mais corpo, rompendo, muitas vezes, com a estrutura de um dia apenas de atividades e entrando no escopo do planejamento das aulas durante a semana, com ressonâncias do projeto em outras atividades curriculares da Professora Cristiane. Sem essa parceria, possivelmente, o projeto não teria acontecido.

34 Utilizei os métodos do Teatro do Oprimido, de Augusto Boal, e jogos teatrais, de Viola Spolin. 
Utilizou-se, muito, o Laboratório de Informática da escola nesses momentos de escrita e sistematização das leituras. No bloco das sensações, também se experimentava ao produzir gestos através do teatro, ou escritas através da literatura e poesia. Os dois momentos misturavam-se nas atividades, muitas vezes, continuando durante as aulas da semana. Além dessas experimentações e sensações na escola, algumas saídas foram realizadas para ampliar o mundo e colorir-se de outras vivências: para cinemas, feira do livro de Porto Alegre, visita em museus, etc.

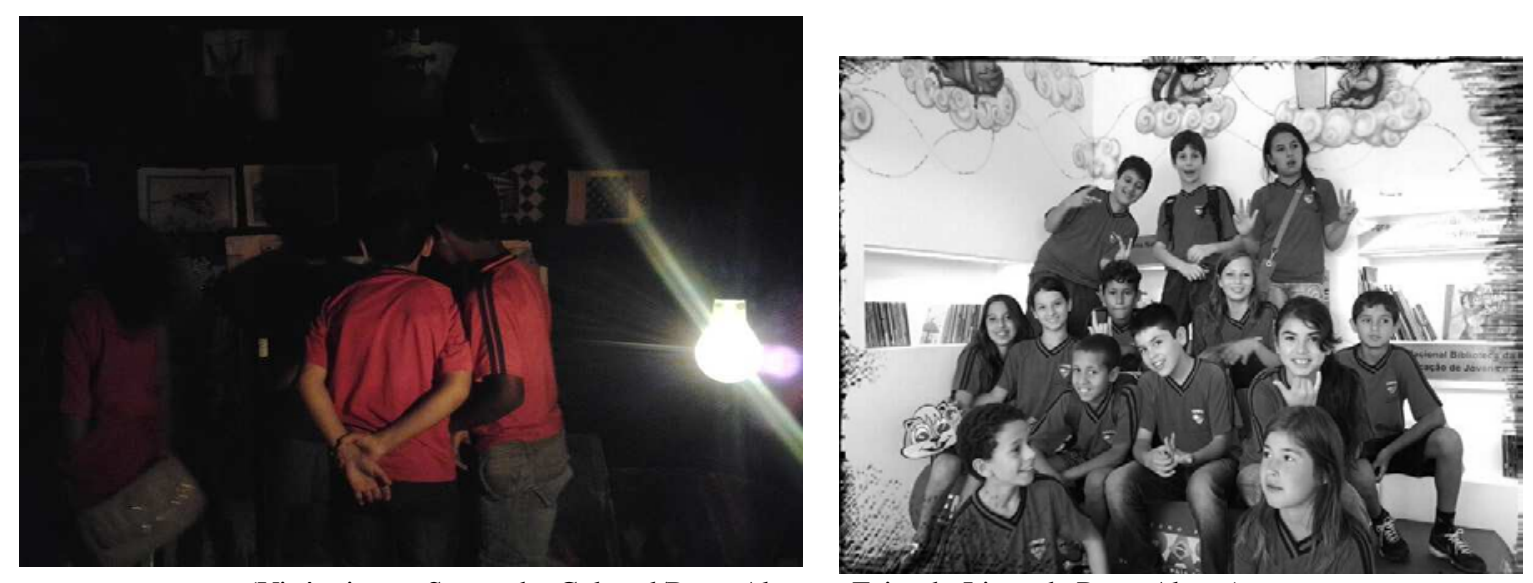

(Vivências no Santander Cultural/Porto Alegre e Feira do Livro de Porto Alegre)

Essa vivência, em sala de aula, ao proporcionar uma experimentação de outros elementos como teatro, literatura, escrita de contos, de poesias, no soltar a criatividade em pinturas e na criação de objetos poéticos, possibilitou o nascimento do documentário 'As cores da Esperança'. A atividade que desencadeou esse audiovisual foi um trabalho sobre quais eram os biografemas da vida deles.

A partir do curta-metragem 'Dona Cristina perdeu a memória ${ }^{35}$, de uma roda de conversa sobre a música 'Gentileza', de Marisa Monte, e da sistematização das gentilezas que realizamos no cotidiano, os alunos tiveram que construir um poema visual sobre gentileza e realizar uma pesquisa na comunidade sobre esse tema. Utilizando o laboratório de informática da escola, tiveram que escrever essas entrevistas realizadas inventando outras memórias.

Após o agenciamento de um audiovisual, de música e de escrita realizou-se uma finalização conversando sobre esses biografemas coletados, essas histórias ouvidas e escritas, e as inventadas por eles. Dessa reflexão surgiu o debate sobre a temática da violência, um dado presente na realidade escolar, da comunidade e da cidade.

Essa temática aparece mostrando a contradição que se vive: de um lado, ações que despertam as potências de vida, as afecções alegres através de gentilezas pequenas e, de outro lado, as ações que produzem afecções tristes. Decidimos trabalhar e explorar mais a temática da cultura de paz, tendo como linha condutora das aulas os tipos de violência que produzimos e que recebemos.

Para ajudar nas discussões, realizamos oficinas de teatro, de música, trabalhando com paródias sobre paz e violência, construção de textos e debates que foram amadurecendo as reflexões sobre os jeitos, as formas e os modos como sofremos e produzimos violências. Dessa cartografia de vid[eo]a, brotou o slogan "Se você tem a cabeça no lugar, violência nem Pensar!”. Do slogan, surgiu a necessidade de colorir e dar outros tons através de um audiovisual e de uma Campanha contra a Violência nas Escolas.

O slogan foi criado pelos próprios alunos. Em um dos momentos de conversa sobre a temática da violência e da cultura de paz, um aluno disse "a gente tem que ter a cabeça no lugar", e um segundo complementou "para parar de pensar só em violência e praticar outras ações”. Coube a uma terceira realizar a junção dessas frases e dar corpo ao slogan.

35 Uma realização da Casa de Cinema de Porto Alegre, de 2002. Mais informações em http://www.casacinepoa.com.br/os-filmes/produ\%C3\%A7\%C3\%A3o/curtas/dona-cristina-perdeu-mem\%C3\%B3ria 
Para chamar a atenção da temática e dar início à campanha, realizou-se uma confecção de cartazes com mãos vermelhas pintadas e distribuídas pelas paredes e corredores da escola. Ao longo de algumas semanas, essa foi a intervenção inicial, uma mão vermelha. A segunda intervenção foi colocar o slogan "Se você tem a cabeça no lugar, violência nem Pensar!" nas mãos e em cartazes.

\section{Se você tem a cabeça no Iugar}

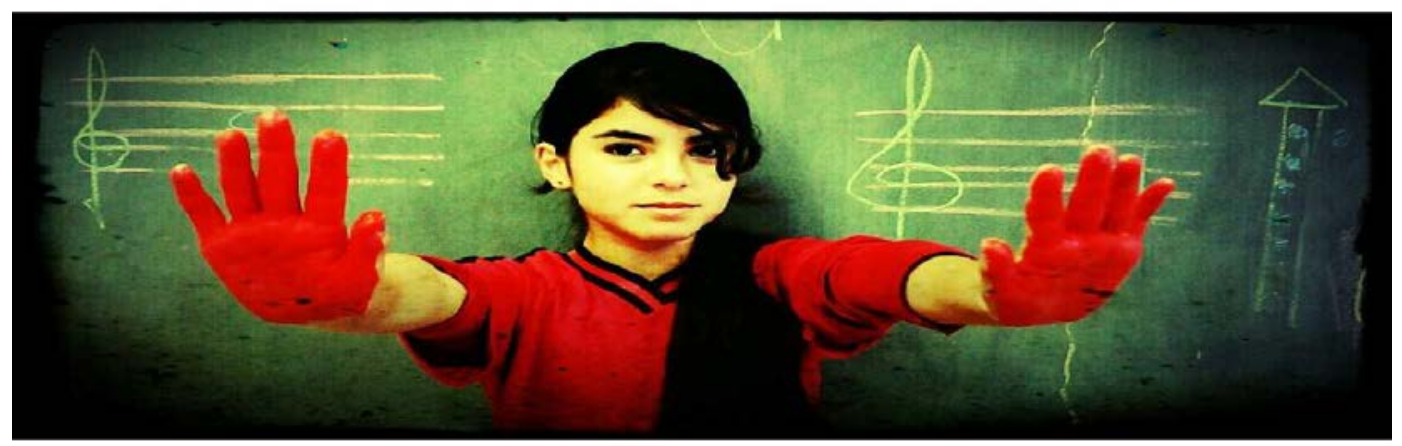

\section{Violência nem Pensar!}

(Cartaz da Campanha “Se você tem a cabeça no lugar, Violência nem Pensar!”)

O documentário 'As Cores da Esperança' nasce do desejo de partilhar um pouco esses biografemas de vida. Realizamos uma conversa com a direção da escola, mostrando a importância de um corpo maior para a campanha. Logo após o aval da direção, partimos para a conversa com os pais e, por fim, a gravação das imagens ${ }^{36}$, edição e finalização.

No final do ano de 2012, o documentário, após várias projeções na escola, nas turmas e dos alunos conversando com outros alunos sobre a campanha, participou da I Mostra Experimental de Curtas-Metragens Curta Inclusão e Diversidade ${ }^{37}$.

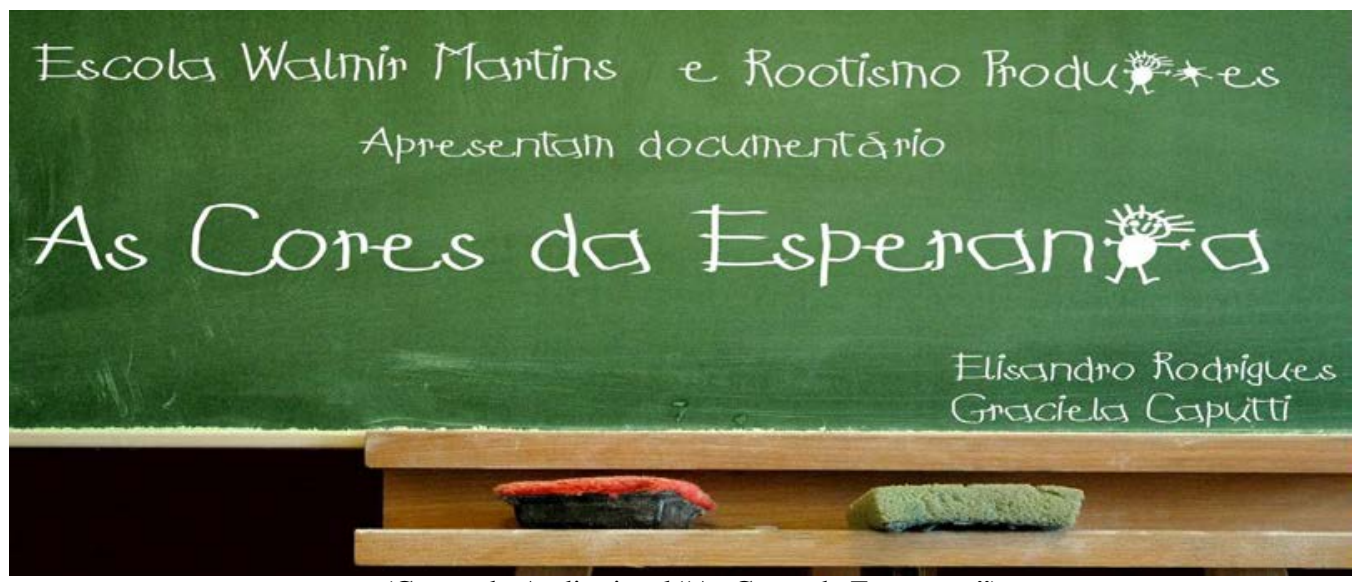

(Cartaz do Audiovisual “As Cores da Esperança”)

36 Este trabalho foi realizado em parceria com a professora titular da turma e com a parceria de Graciela Caputti, que realizou a captação das imagens. A edição foi realizada por mim.

37 A Mostra Experimental de Curtas-Metragens Curta Inclusão e Diversidade iniciou-se, em 2012, e está indo para a sua terceira edição. Nasceu dos projetos de acompanhamento de crianças e adolescentes em processos de inclusão escolar do Setor de Educação Inclusiva e Diversidade, da Secretaria Municipal de Educação do município de Novo Hamburgo. A I Mostra Experimental de Curtas-Metragens teve seu tema inicial 'Curta Inclusão e Diversidade', que ganhou status de marca nas edições posteriores. Nessa primeira experimentação, em 2012, teve 27 curtas-metragens inscritos. Destes, 23 eram de escolas do município de Novo Hamburgo, 2 de Centros de Atenção Psicosocial e 2 de outras cidades do entorno. O objetivo da Mostra não é de competição, sendo assim, todos os inscritos são selecionados e seus audiovisuais passam nos espaços da Mostra. Nos últimos dois anos, os espaços constaram com a projeção no cinema da cidade e no Teatro Municipal. O nome do troféu da Mostra já diz isso: UBUNTU, palavra africana que, entre outros significados, significa "humanidade”. 


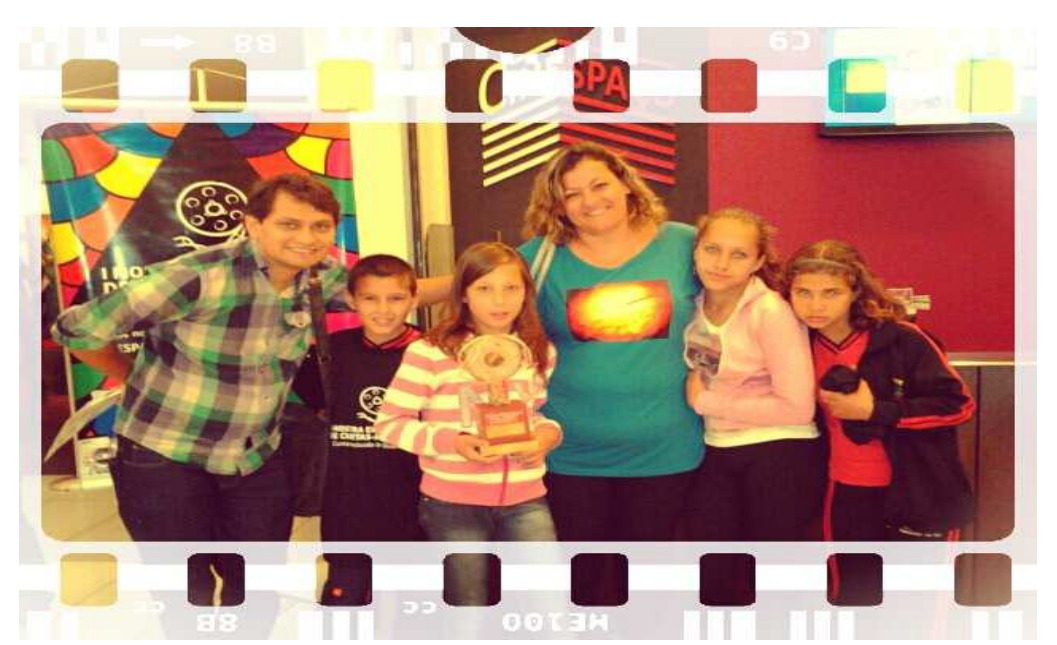

(Participação do Audiovisual “As Cores da Esperança” na Mostra Curta Inclusão de Novo Hamburgo)

Ao analisarmos essa experiência, nota-se que um tipo de violência foi realizado, a do pensar, para transgredir com o assujeitamento e a mortificação do currículo escolar, rompendo com modos cristalizados de trabalhar os conteúdos em sala de aula e produzindo outros modos de vida. O trabalho em sala de aula, utilizando o teatro, a literatura e o audiovisual, produziu afectos e afecções nos alunos e nos professores envolvidos.

No final do documentário, um fragmento poético salta, o qual diz o seguinte: "me desculpe a delicadeza a cor da esperança me descortina para o dia”,38. As ressonâncias e as escritas de si foram acompanhadas durante os processos de construção cotidiana do aprendizado e das experimentações vividas. $\mathrm{O}$ novo. $\mathrm{O}$ diferente. $\mathrm{O}$ outro. $\mathrm{O}$ que se criou foram produtos que dizem deles. De suas vidas, de seus biografemas. E assim como é difícil fotografar o silêncio, é dificil dizer dessas marcas que ficam. Mas as cores de uma esperança descortinaram outros dias e outros modos de agenciar o ensino e a aprendizagem.

O audiovisual, por exemplo, carregado de afetos alegres anda de mãos dadas com os afetos tristes, nessa variação de intensidades, nessa mistura que sustenta a vida como ela é. Geralmente, as pessoas somam as infelicidades, as tristezas, contando instante quaisquer por instante quaisquer, o que vemos, em Spinoza e em Deleuze, é que devemos realizar o inverso, o avesso disso. Em vez de contarmos as nossas paixões tristes, somamos e multiplicamos as alegres.

Ao produzir, junto aos alunos, o audiovisual 'As Cores da Esperança', experimentei a potência de agir que está nas imagens e em um processo pedagógico que utiliza tecnologias que podem ser criadas e inventadas. Escrever essa experiência é dar atenção a esses instantes quaisquer, a essa a[in]cidente, a esses pormenores que acontecem nos ambientes escolares e, na maioria das vezes, não são compartilhados.

O audiovisual é, para mim, uma possibilidade de trabalhar com um intervalo de tempo, com um instante, espaço, ponto quaisquer ${ }^{39}$, nosso pormenor, que interage com quem está assistindo, possibilitando agenciamentos educacionais e pedagógicos. Aprendemos quando somos capturados, afetados pelas imagens, pelos sons. Os afetos estão nos pequenos pormenores que vivenciamos, nesse movimento que produz o novo, pois "quando reportamos o movimento a momentos quaisquer, devemos nos tornar capazes de pensar a produção do novo”,40. O projeto 'Cartografias Infantis: Biografemas de Instantes Quaisquer' é um exemplo dessa produção do novo em sala de aula.

39 “É nesse sentido que o cinema é o sistema que reproduz o movimento em função do instante qualquer, isto é, em função de momentos equidistantes, escolhidos de modo a dar a impressão de continuidade” [DELEUZE, 1985, p. 13]. 40 [DELEUZE, 1985, p. 16] 
Não houve uma expansão do audiovisual a contento na educação ${ }^{41}$, geralmente, o vídeo, o filme é usado como passatempo nas salas de aula. Mas, aos poucos, ele vem sendo tomado como importante nos processos de aprendizagem, ocupando um lugar de destaque como Objeto de Aprendizagem ${ }^{42}$."Usado como elemento na forma de objeto de aprendizagem”, o audiovisual "é referido aqui como recurso pedagógico que se vale da linguagem audiovisual para desenvolver atitudes perceptivas múltiplas” ${ }^{33}$.

Dessa forma, ao falar dessa cartografia que se experimentou com os alunos. Dessa mistura que se realizou, nesse intervalo de tempo, onde a arte, o teatro, a literatura, a poesia, o audiovisual se encontraram. E de onde brotou essa produção do documentário 'As Cores da Esperança'. Quero falar que não sabíamos, ao certo, onde iríamos, mas que, ao misturar e proporcionar aos alunos outras sensações e experimentações, o audiovisual, enquanto imagem, foi um afecto e uma afecção.

\section{\#}

Deleuze $^{44}$, fala-nos que os processos de ruptura são singelos deslocamentos de construção de outros sentidos que intitula de perceptos. Perceptos não é percepção, mas sim, um conjunto de sensações e percepções que vai além daquele que sente, que se propagam, que escoam. Percepto é esse instante, esse intervalo que cria outras sensações, nos deslocando, criando um tremor na nossa percepção.

Diz o autor que não existem perceptos sem afectos, e os afectos seriam os devires. Devires que brotam naqueles que olham um audiovisual, que transbordam ao simples captar as imagens, ao editar, ao cortar, montar o produto final. Afectos é o lugar da fusão ${ }^{45}$, desse entrosamento de imagens e sons que produzem pormenores que são captados pelo olhar, pelo escutar. Fischer ${ }^{46}$ dirá que "poeticamente os afetos podem ser chamados como paixões da alma que se movimentam entre a razão e a emoção, entre o sujeito e o objeto, alcançando assim um estado potente e latente”.

Podemos dizer que o audiovisual "não apresenta apenas imagens, ele as cerca com um mundo"47, ou mundos em uma variação. Quando somos afetados [afectados] por uma força, entramos em um processo de variação de nossa força de existir ${ }^{48}$, ou potência de agir. Um afecto, portanto, é uma potência de agir.

Para Spinoza "a ideia que constitui a forma de um afeto deve indicar ou exprimir o estado do corpo ou de alguma de suas partes, estado que o próprio corpo ou de alguma de suas partes, tem porque sua potência de agir ou sua força de existir é aumentada ou diminuída, estimulada ou refreada, ${ }^{49}$.

Essa potência, ou força de agir, sofre uma variação, pois pode ser aumentada ou diminuída pelos encontros [ou paixões, para Spinoza] alegres ou tristes que realizamos. Deleuze $^{50}$ fala-nos que nossa potência de agir ou nossa força de existir é aumentada ou é diminuída de uma maneira contínua, sobre uma linha contínua, e é isso que nós chamamos de afeto [affectus], é isso que nós chamamos de existir.

Dessa forma, tanto para Spinoza quanto para Deleuze, o afeto [affectus] é uma variação contínua de instantes quaisquer, de a[in]cidentes, de nossa força de existir, de nossa potência de agir.

Já a afecção [affectio] é o estado de quem sofre uma ação de afeto [afecto], ou a ação de

41 [TIELLET, 2010, p. 50]

42 Ibd.

43 [TIELLET, 2010, p. 51]

44 No seu Abecedário, uma série de entrevistas realizadas por Claire Parnet entre os anos de 1988 e 1989, e divulgadas apenas entre 1994 e 1995. Essas entrevistas estão disponibilizadas na internet em vídeo e também transcritas.

45 [DELEUZE; GUATTARI, 1997, p. 218]

46 [2012, p. 186]

47 [DELEUZE, 2005, p. 87]

48 [SPINOZA, 2011, p. 152]

49 [Ibd.,]

50 No seus seminário sobre Spinoza, ainda não publicado no Brasil, mas disponível e traduzido no endereço http://www.webdeleuze.com/php/texte.php?cle=194\&groupe=Spinoza\&langue=5 . 
um outro corpo sobre o seu. Deleuze ${ }^{51}$ dá um exemplo muito claro sobre essa afecção. Quando estamos sobre o sol, estamos sofrendo um efeito do sol sobre nosso corpo, essa ação sempre implicará um contato, para o autor, uma mistura dos corpos. Dessa forma, o sol está entrando em contato com meu corpo, está me aquecendo, misturando-se com meu próprio corpo. Sendo assim, a afecção é sempre essa mistura.

Nas palavras de Spinoza, "por afeto compreendo as afecções do corpo, pelas quais sua potência de agir é aumentada ou diminuída, estimulada ou refreada, e ao mesmo tempo, as ideias dessas afecções. Assim, quando podemos ser a causa adequada de alguma dessas afecções, por afeto compreendo, então, uma ação; em caso contrário, uma paixão”, ${ }^{, 52}$.

Dessa forma, a imagem, e o audiovisual, como um agenciamento de a[in]cidentes, de movimentos, de vibrações e variações produzem afectos e afecções. Criam uma intensidade para nossas potências de agir e de viver uma vida, pois, "qualquer coisa pode ser, por acidente, causa de alegria, de tristeza ou de desejo" ${ }^{, 3}$.

Deleuze se pergunta "será que a música não seria a grande criadora de afectos? Será que ela não nos arrasta para potências acima de nossa compreensão?”. Podemos perguntar dessa forma o mesmo para o audiovisual, será que o audiovisual não seria um grande criador de afectos $^{54}$ ?

$$
\text { \# }
$$

\section{Conclusão}

Ao olharmos para esta experiência de trabalho em sala de aula, que cresce pelo meio, com sistematização de um audiovisual, percebemos que o audiovisual pode ser usado para potencializar não só os olhares, mas as vidas de quem está participando desse processo de captação de imagens e de projeção, seja na tela de cinema ou em uma televisão em sala de aula.

O audiovisual, como uma afecção, tem a potência de furar, de fazer vazar para as vidas, outros sentidos potencializando os pormenores de cada processo, de cada vivência, os instantes quaisquer que lançam para um outro jeito de viver e de pensar a educação.

Trazendo novamente Ulpiano, o mesmo diz que a arte seria a única maneira que nós teríamos de escapar do sufocamento da vida que vivemos. São, nesses instantes quaisquer, captados pela objetiva de uma câmera de celular, de máquina fotográfica amadora ou profissional, que nossa vida pode escapar, pode escoar outras imagens ainda não pensadas.

Acredito que o uso dessa tecnologia seja um processo de [des]construção dos atuais jeitos que vivemos e pensamos a educação. Utilizar o audiovisual como dispositivo, como ferramenta, de pensamento mostra-se importante no processo de aprendizagem, de formação e de vivenciar outros possíveis.

Entendo dessa forma o audiovisual, como uma potência de afetação ${ }^{55}$, através de instantes quaisquer, provocados pelos a[in]cidentes $\mathrm{n}[\mathrm{d}] \mathrm{a}$ imagem. Somos afetados pelas imagens que vemos na tela [do cinema, da televisão, do computador, do celular] e produzimos afetos após essa afecção.

Iniciei esse artigo falando das imagens poéticas e da captura desses jeitos por uma lente de uma máquina analógica. Penso que essas capturas poéticas são realizadas quando os alunos de uma escola, ou de um projeto, contam suas vidas através do que capturam, dos pequenos biografemas que criam. Ao se proporem gravar, captar imagens, já estão contando uma vida e possibilitando outros olhares sobre a vida.

Ao contar uma vida, desteritorializam o que antes estava cristalizado, compactado, endurecido, possibilitando novos jeitos e novas formas de fazer. A produção e a criação de um audiovisual mostra-se um dispositivo de desteritorialização, de criação de uma vida [ou várias], multiplicando a potência afetiva e poética.

"Guatarri tem uma expressão muito bonita sobre isso: ele diz que os afetos colam na

\footnotetext{
51 [Ibid.,]

52 [SPINOSA, 2011, p. 98]

53 [Ibd., p. 109]

54 Realizando uma síntese, utilizando Spinoza, "a afecção é o aqui e o agora, enquanto o afeto é a passagem. A afecção implica o afeto, embora entre os dois haja diferença de natureza: a afecção é o instantâneo, o afeto é o devir” [ULPIANO, 2013, p. 163].

55 [DELEUZE, 2005, p.170]
} 
subjetividade" ${ }^{\text {56 }}$. Entende-se, dessa forma, que o espaço da sala de aula, como instante quaisquer, é o lugar onde os afetos acontecem, onde se expressam. E que podem ser agenciados com o uso de tecnologias leves e de invenção, podendo escoar imagens e contar vidas, jeitos, bem como uma outra educação possível através do audiovisual.

\section{_Referências}

AUDINO, Daniel Fagundes; NASCIMENTO, Rosemy da Silva. Objetos de Aprendizagem Diálogos entre conceitos e uma nova proposição aplicada à educação. Revista Contemporânea de Educação. Santa Catarina, Vol. 5, n. 10, jul/dez 2010.

AGUIAR, Lisiane Machado; ROSÁRIO, Nísia Martins do. Pluralidade Metodológica: a cartografia aplicada às pesquisas de audiovisual. Revista Comunicación, $n^{\circ} 10$, Vol. 1, 2012, pg.1262-1275.

BARROS, Manoel de Barros. Poesia Completa. São Paulo:Leya, 2010.

BARTHES, Roland. A câmara clara. Lisboa : Edições 70, 2010. Incidentes. São Paulo: Martins Fontes, 2004.

. O império dos signos. São Paulo: Martins Fontes, 2007.

PASSOS, Eduardo; KASTRUP, Vírginia; ESCÓSSIA, Liliane (org). Pistas do método da cartografia: pesquisa-invenção e produção de subjetividade. Porto Alegre: Sulina, 2009.

COLVERO, Luciana de Almeida; MACHADO, Ana Lucia; MARTINES, Wânia R. V. A Cartografia com inovação metodológica na pesquisa em saúde. Revista Tempus Actas de Saúde Coletiva, p. 203-211, 2013.

DELEUZE, Gilles e GUATTARI, Félix. Mil Platôs: capitalismo e esquizofrenia. Rio de Janeiro: Ed. 34, 1997. V.4.

. O que é flosofa. Rio de Janeiro: Ed 34, 1997.

DELEUZE, Gilles. Cinema 1. A Imagem-Movimento. São Paulo: Brasiliense, 1985.

. Cinema 2. A Imagem-Tempo. São Paulo: Brasiliense, 2005.

FISCHER, Rodrigo Desider. Investigações sobre fotogenia: produções de afetos no cinema de John Cassavetes. Revista Rumores, edição 11, jan-jun, p. 180-199, 2012.

FREITAS, M.C de A; MACHADO, L.D. Uma resenha bricolada de "Pesquisar na Diferença - um abecedário”. Revista Mnemosine. Vol. 9, n.1, p. 238-244, 2013.

FOUCAULT, M. Estratégia, Poder-Saber. Ditos e Escritos IV. Rio de Janeiro: Forense Universitária, 1994.

KIRST, Patrícia; FONSECA, Tânia Mara Galli. Somos Imagens: o mundo é imagem. Informática na Educação: teoria \& prática, Porto Alegre, v. 11, n.2, p.34-38, jul./dez. 2008.

MACHADO, L. L.; SILVA, J. T. Objeto de aprendizagem digital para auxiliar o processo de ensino-aprendizagem no Ensino Técnico em Informática. RENOTE - Revista Novas Tecnologias na Educação, Porto Alegre: UFRGS, CINTED, v. 3, n.2, 2005.

MEYER, Dagmar Estermann; PARAISO, Marlucy Alves (orgs.). Metodologias de pesquisas pós-críticas em educação. Belo Horizonte: Mazza Edições, 2012.

MERHY, E. E. Saúde: A Cartografia do Trabalho Vivo; São Paulo, Hucitec, 2002. NAPOLITANO, Marcos. Fontes audiovisuais: a história depois do papel. In: PINSKY, Carla (org). Fontes históricas. São Paulo: Contexto, 2005.

. Como usar o cinema em sala de aula. São Paulo: Contexto, 2003.

56 Claudio Ulpiano comenta isso em sua aula do dia 24/07/1995 sobre Imagem-afecção. 
REIS, S.C. Do discurso à prática: textualização de pesquisas sobre ensino de inglếs mediado por computador, Tese de Doutorado, Universidade Federal de Santa Maria, Santa Maria, RS, 2010.

ROSÁRIO, Nísia Martins; AGUIAR, Lisiane Machado. Pluralidade metodológica: a cartografia aplicada às pesquisas de audiovisual. Revista Comunicación, $\mathrm{N}^{\circ} 10$, Vol. 1, 2012. P. $1262-1275$.

SOUSA, Edson. Uma Invenção da Utopia. São Paulo: Lume Editor, 2007.

SPINOZA. Ética [tradução de Tomaz Tadeu]. Belo Horizonte: Autêntica Editora, 2011.

TIELLET, Claudio Afonso Baron. Construção e Avaliação do Hipervídeo como Ferramenta Auxiliar para Aprendizagem de Cirurgia, 2010. Tese (Doutorado), Centro Interdisciplinar de Novas Tecnologias na Educação. Programa de Pós-Graduação em Informática na Educação, Universidade Federal do Rio Grande do Sul, Porto Alegre.

ULPIANO, Claudio. Gilles Deleuze: A Grande aventura do pensamento. Rio de Janeiro: Funemac Livro, 2013.

VASCONCELLOS, Jorge. A filosofia e seus intercessores: Deleuze e a não-filosofia. Educ. Soc.[online]. 2005, vol.26, n.93, pp. 1217-1227. Disponível em: <http://www.scielo.br/pdf/es/v26n93/27276.pdf > Acesso em: 29 de Junho de 2012.

A pedagogia da imagem: Deleuze, Godard - ou como produzir um pensamento do cinema. In:Educação \& Realidade. Porto Alegre, Faculdade de Educação/UFRGS, jan/jun 2008, 33(1), p. 155-168.

\section{Audiovisuais Citados}

Matéria de Poesia - https://vimeo.com/77271234

Das cores da esperança - https://vimeo.com/52952861 